\title{
STUDYING THE EFFECT OF A COMBINATION OF PLANT GROWTH REGULATOR ON MULTIPLE SHOOTS AND ROOTING IN GmCHI TRANSGENIC T. PANICULATUM
}

Vu Thi Nhu Trang ${ }^{2 *}$, Chu Hoang Mau ${ }^{1}$, Ngo Thi Thuy Ngan ${ }^{2}$

${ }^{I} T N U$ - University of Education

${ }^{2} T N U$ - University of Medicine and Pharmacy

\begin{tabular}{|c|c|}
\hline ARTICLE INFO & ABSTRACT \\
\hline Received: $28 / 5 / 2021$ & \multirow{7}{*}{$\begin{array}{l}\text { Talinum paniculatum is a herbaceous plant known for its high } \\
\text { medicinal value. GmCHI transgenic } T \text {. paniculatum in the T1 } \\
\text { generation, that contain } 4.24 \mathrm{mg} / \mathrm{g} \text { and } 2.74 \mathrm{mg} / \mathrm{g} \text { of flavonoid, } \\
\text { respectively, which reflect increases of } 7.4 \text {-fold and } 4.8 \text {-fold, } \\
\text { respectively, compared to that in wild-type plants. In order to increase } \\
\text { flavonoid acquisition from the biomass of GmCHI transgenic } T \text {. } \\
\text { paniculatum in the } \mathrm{T} 1 \text { generation with high flavonoid content, it is } \\
\text { necessary to study the effect of multiple shoots and rooting in } \\
\text { transgenic plants. In this paper, we present the results of studying the } \\
\text { effects of a combination of plant growth regulator on multiple shoots } \\
\text { and rooting in GmCHI transgenic } T \text {. paniculatum. The cotyledons are } \\
\text { suitable materials to create multiple shoot for } G m C H I \text { transgenic } T \text {. } \\
\text { paniculatum when using the MS medium supplemented with } \\
\text { kinetin. The addition of } 2.0 \mathrm{mg} / \mathrm{l} \text { of BAP gave a higher multi-shooting } \\
\text { effect than the addition of } 1.5 \mathrm{mg} / \mathrm{l} \text { of kinetin or the combination of } 1.5 \\
\text { mg/l of kinetin with } 0.8 \mathrm{mg} / \mathrm{l} \text { of IBA. Using } 0.5 \mathrm{mg} / \mathrm{l} \text { IAA had better } \\
\text { rooting ability than combining } 0.5 \mathrm{mg} / \mathrm{l} \text { IAA with kinetin. }\end{array}$} \\
\hline KEYWORDS & \\
\hline Culture medium & \\
\hline Multiple shoots & \\
\hline GmCHI transgenic T. paniculatum & \\
\hline The cotyledons & \\
\hline Plant growth regulator & \\
\hline
\end{tabular}

\section{NGHIÊN CÚU ẢNH HƯởNG CỦA TỔ HợP CÁC CHẤT KÍCH THÍCH SINH TRƯởNG LÊN SƯ PHÁT SINH CHỒI VÀ RA RẼ Ở CÂY THỔ NHÂN SÂM CHUYỂN GEN GmCHI}

\author{
Vũ Thị Như Trang ${ }^{*}$, Chu Hoàng Mậu', Ngô Thị Thúy Ngân² \\ ${ }^{1}$ Truoòng Đại hoc Su phạm - ĐH Thái Nguyên, \\ ${ }^{2}$ Truoòng Đại học Y Duợc - ĐH Thái Nguyên
}

\begin{tabular}{|c|c|}
\hline THÔNG TIN BÀI BÁO & \multirow{10}{*}{$\begin{array}{l}\text { TOM TAT } \\
\text { Thổ nhân sâm (Talinum paniculatum) là loại cây thân thảo được biết } \\
\text { đến với giá tri dược liệu cao. Cây Thổ nhân sâm chuyển gen } G m C H I \\
\text { ở thế hệ T1 có hàm lượng flavonoid tổng số tăng } 7,4 \text { lần và } 4,8 \text { lần so } \\
\text { với cây đối chứng không chuyển gen. Để tăng thu nhận flavonoid từ } \\
\text { sinh khối của các cây Thổ nhân sâm chuyển gen ở thế hệ T1 có hàm } \\
\text { lượng flavonoid cao thì việc nghiên cứu hiệu quả tạo đa chồi và ra rễ } \\
\text { ở cây chuyển gen là cần thiết. Trong bài báo này, chúng tôi trình bày } \\
\text { kết quả nghiên cứu ảnh hưởng của tổ hợp các chất kích thích sinh } \\
\text { trưởng lên sự phát sinh chồi và ra rễ ở cây Thổ nhân sâm chuyển gen } \\
\text { GmCHI. Đoạn thân mang mắt chồi bên là vật liệu thích hợp để tạo đa } \\
\text { chồi khi sử dụng môi trường MS cơ bản bổ sung kinetin. Bổ sung } 2,0 \\
\text { mg/l BAP cho hiệu quả đa chồi cao hơn so với bổ sung } 1,5 \text { mg/l kinetin } \\
\text { hay kết hợp } 1,5 \text { mg/l kinetin với } 0,8 \text { mg/l IBA. Sử dụng } 0,5 \text { mg/l IAA có } \\
\text { khả năng tạo rễ tốt hơn so với kêt hợp } 0,5 \text { mg/l IAA với kinetin. }\end{array}$} \\
\hline Ngày nhận bài: 28/5/2021 & \\
\hline Ngày hoàn thiện: 09/8/2021 & \\
\hline $13 / 9 / 2021$ & \\
\hline TU் KHÓA & \\
\hline Môi trường nuôi cấy & \\
\hline Đa chồi & \\
\hline $\begin{array}{l}\text { Cây Thổ nhân sâm chuyển gen } \\
G m C H I\end{array}$ & \\
\hline I thân mang mă & \\
\hline & \\
\hline
\end{tabular}

DOI: $\underline{\text { https://doi.org/10.34238/tnu-jst.4559 }}$

\footnotetext{
* Corresponding author. Email: nhutrang.dhyktn@gmail.com
} 


\section{Mở đầu}

Thổ nhân sâm (Talinum paniculatum) là loại cây thân thảo được biết đến với giá trị dược liệu cao. Các nghiên cứu về thành phần hóa học của cây Thổ nhân sâm cho thấy, trong lá và rễ có rất nhiều các hợp chất có hoạt tính sinh học khác nhau như: alkaloid, flavonoid, saponin, tannin, phytosterol, phytol; trong đó các phytol chiếm tỷ lệ cao (69,32 \%) [1], [2]. Đặc biệt, flavonoid là một hợp chất có vai trò quan trọng đối với con người như có tác dụng chống oxy hóa, bảo vệ gan, kháng khuẩn, chống viêm, chống ung thư...[3], [4]. Cây Thổ nhân sâm chuyển gen $G m C H I$ ở thế hệ $\mathrm{T} 1$ có hàm lượng flavonoid tổng số tăng 7,4 lần và 4,8 lần so với cây đối chứng không chuyển gen [5]. Gen chuyển ở thế hệ $\mathrm{T} 2, \mathrm{~T} 3 \ldots$ sẽ bị phân ly, do đó cần phải phân tích, đánh giá và chọn lọc. Chính vì vậy, để tăng thu nhận flavonoid từ sinh khối của các cây Thổ nhân sâm chuyển gen ở thế hệ $\mathrm{T} 1$ có hàm lượng flavonoid cao thì cần thiết phải nghiên cứu hiệu quả tạo đa chồi và ra rễ ở cây chuyển gen, từ đó các cây nuôi cấy in vitro sẽ giữ nguyên đặc tính di truyền của cây $\mathrm{T}$ 1. Trong nghiên cứu [6], các tác giả đã nghiên cứu hệ thống tái sinh in vitro phục vụ chuyển gen ở cây Thổ nhân sâm. Trong đó, đã xác định được ảnh hưởng của BAP, IBA đến hiệu quả tạo đa chồi và IAA, NAA đến khả năng ra rễ ở cây Thổ nhân sâm. Tuy nhiên, các tác giả chưa nghiên cứu ảnh hưởng của kinetin và ảnh hưởng kết hợp của kinetin với BAP, IAA, NAA lên sự phát sinh chồi và ra rễ ở cây Thổ nhân sâm. Đồng thời, đối tượng nghiên cứu là cây Thổ nhân sâm chưa chuyển gen [6].

Trong bài bào này, chúng tôi sẽ trình bày kết quả nghiên cứu ảnh hưởng của tổ hợp các chất kích thích sinh trưởng lên sự phát sinh chồi và ra rễ ở cây Thổ nhân sâm chuyển gen $G m C H I$.

\section{Vật liệu và phương pháp}

Hạt của cây Thổ nhân sâm chuyển gen $G m C H I$ T0-2.2 và T0-10 được sử dụng làm nguyên liệu nuôi cấy in vitro. Khử trùng hạt Thổ nhân sâm bằng cồn $70 \%$ trong thời gian 1 phút, rửa sạch bằng nước cất, sau đó khử trùng hạt bằng dung dịch javel $60 \%$ với thời gian 10 phút. Rửa sạch hạt bằng nước cất vô trùng 8 lần, sau đó cấy lên môi trường MS cơ bản tạo vật liệu in vitro để nghiên cứu [6].

Nghiên cứu ảnh hương của kinetin đến sụ phát sinh và sinh trương chồi tù̀ nách lá mầm của cây Thổ nhân sâm chuyển gen GmCHI: Lá mầm 2 tuần tuổi được gây tổn thương bằng mũi kim nhọn ở nách lá, sau đó cấy lên môi trường MS cơ bản, bổ sung kinetin $0,5 \mathrm{mg} / \mathrm{l} ; 1,0 \mathrm{mg} / \mathrm{l} ; 1,5$ $\mathrm{mg} / \mathrm{l} ; 2,0 \mathrm{mg} / \mathrm{l}$. Sự phát sinh chồi và sinh trưởng của chồi được đánh giá bằng các chỉ tiêu về số chồi/mẫu, chiều cao chồi, số lá/chồi, chất lượng chồi sau 2 tuần và 4 tuần nuôi cấy.

Nghiên cứu ảnh hưởng kinetin, BAP và ành hưởng kết hợp của kinetin tối ưu, BAP tối uu với IBA đến sự phát sinh và sinh trưởng chồi từ đoạn thân mang mắt chồi bên Thổ nhân sâm chuyển gen GmCHI: Đoạn thân có kích thước 1,0 - 1,5 cm mang mắt chồi bên sau $6-8$ tuần nuôi cấy được gây tổn thương bằng dao chẻ dọc qua giữa 2 mắt chồi bên, dùng kim châm gây tổn thương ở mắt chồi bên, sau đó cấy lên môi trường MS cơ bản, bổ sung kinetin $0,5 \mathrm{mg} / 1 ; 1,0 \mathrm{mg} / \mathrm{l} ; 1,5 \mathrm{mg} / \mathrm{l} ; 2,0$ $\mathrm{mg} / \mathrm{l} ; 2,5 \mathrm{mg} / \mathrm{l}$; bổ sung BAP 0,5 mg/l; 1,0 mg/l; 1,5 mg/l; 2,0 mg/l; 2,5 mg/l; 3,0 mg/l. Tiếp theo nghiên cứu ảnh hưởng kết hợp của kinetin và $\mathrm{BAP}$ ở nồng độ tối ưu với IBA $0,2 \mathrm{mg} / \mathrm{l} ; 0,4 \mathrm{mg} / \mathrm{l} ; 0,6$ $\mathrm{mg} / \mathrm{l} ; 0,8 \mathrm{mg} / \mathrm{l} ; 1,0 \mathrm{mg} / \mathrm{l}, 1,2 \mathrm{mg} / \mathrm{l}$. Sự phát sinh và sinh trưởng của chồi được đánh giá bằng các chỉ tiêu về số chồi/mẫu, chiều cao chồi, số lá/chồi, chất lượng chồi sau 2 tuần và 4 tuần nuôi cấy.

Nghiên cứu ảnh huoơng kết hợp của kinetin với $0,5 \mathrm{mg} / \mathrm{l} I A A$ và $0,5 \mathrm{mg} / \mathrm{l}$ NAA đến khả năng ra rễ của cây Thổ nhân sâm chuyển gen GmCHI: Sử dụng chồi tái sinh 4 - 6 tuần nuôi cấy in vitro có kích thước $1,0-1,5 \mathrm{~cm}$ cấy lên môi trường MS cơ bản, bổ sung $0,5 \mathrm{mg} / \mathrm{l} \mathrm{IAA}$ và $0,5 \mathrm{mg} / \mathrm{l}$ NAA kết hợp với kinetin $0,3 \mathrm{mg} / \mathrm{l} ; 0,5 \mathrm{mg} / 1 ; 0,7 \mathrm{mg} / 1 ; 0,9 \mathrm{mg} / \mathrm{l} ; 1,1 \mathrm{mg} / \mathrm{l}$. Khả năng ra rễ của cây Thổ nhân sâm được đánh giá bằng số lượng rễ/chồi, chiều dài rễ sau 2 tuần và 4 tuần nuôi cấy.

Mỗi công thức thí nghiệm lặp lại 3 lần, mỗi lần đánh giá 30 mẫu. Các số liệu được xử lí trên máy vi tính bằng chương trình Excel với trị số $\bar{X} \pm \mathrm{S}_{\bar{X}}[7]$. 


\section{Kết quả và thảo luận}

\subsection{Anh hưởng của kinetin đến sự phát sinh và sinh trưởng chồi tù̀ nách lá mầm}

Kết quả phân tích ảnh hưởng của kinetin đến sự phát sinh và sinh trưởng chồi từ nách lá mầm được trình bày ở bảng 1 .

Bảng 1. Anh hưởng của kinetin đến sự phát sinh và sinh trương chồi tù nách lá mầm $(n=30)$

\begin{tabular}{|c|c|c|c|c|c|c|}
\hline $\begin{array}{c}\text { Nồng độ } \\
\text { kinetin (mg/l) }\end{array}$ & $\begin{array}{c}\text { Số mẫu tạo } \\
\text { chồi }\end{array}$ & $\begin{array}{c}\text { Số } \\
\text { chồi/mẫu }\end{array}$ & $\begin{array}{c}\text { \% so với } \\
\text { đối chứng }\end{array}$ & $\begin{array}{l}\text { Chiều cao } \\
\text { chồi (cm) }\end{array}$ & Số lá/chồi & $\begin{array}{c}\text { Chất lượng } \\
\text { chồi }\end{array}$ \\
\hline & & & Sau 2 tuần & & & \\
\hline 0 & $12,05 \pm 0,22$ & $1,05 \pm 0,16$ & 100 & $0,62 \pm 0,17$ & $3,11 \pm 0,19$ & $\mathrm{~K}$ \\
\hline 0,5 & $16,32 \pm 0,19$ & $1,34 \pm 0,21$ & 127,61 & $0,71 \pm 0,14$ & $3,51 \pm 0,21$ & TB \\
\hline 1,0 & $21,25 \pm 0,18$ & $1,52 \pm 0,19$ & 144,76 & $0,79 \pm 0,17$ & $4,02 \pm 0,22$ & $\mathrm{~T}$ \\
\hline 1,5 & $25,42 \pm 0,21$ & $1,88 \pm 0,21$ & 179,05 & $0,85 \pm 0,19$ & $4,52 \pm 0,23$ & $\mathrm{~T}$ \\
\hline 2,0 & $22,21 \pm 0,22$ & $1,51 \pm 0,23$ & 143,80 & $0,73 \pm 0,20$ & $4,65 \pm 0,21$ & TB \\
\hline & & & Sau 4 tuần & & & \\
\hline 0 & $12,38 \pm 0,19$ & $1,10 \pm 0,19$ & 100 & $1,85 \pm 0,16$ & $5,21 \pm 0,19$ & $\mathrm{~K}$ \\
\hline 0,5 & $17,01 \pm 0,18$ & $1,43 \pm 0,21$ & 130,00 & $2,32 \pm 0,19$ & $5,65 \pm 0,18$ & $\mathrm{~TB}$ \\
\hline 1,0 & $21,55 \pm 0,22$ & $1,61 \pm 0,23$ & 146,36 & $2,45 \pm 0,23$ & $5,87 \pm 0,22$ & $\mathrm{~T}$ \\
\hline 1,5 & $25,92 \pm 0,18$ & $1,98 \pm 0,17$ & 180,00 & $2,78 \pm 0,19$ & $6,05 \pm 0,21$ & $\mathrm{~T}$ \\
\hline 2,0 & $21,89 \pm 0,22$ & $1,58 \pm 0,21$ & 150,47 & $2,76 \pm 0,18$ & $6,12 \pm 0,22$ & $\mathrm{~TB}$ \\
\hline
\end{tabular}

Chú thích: T: chồi tốt; K: chồi kém; TB: chồi trung bình

Kết quả ở bảng 1 cho thấy, môi trường MS bổ sung kinetin $0,5-2,0 \mathrm{mg} / \mathrm{l}$ có số chồi tăng so với đối chứng từ $27,61 \%$ đến $43,8 \%$ (ở giai đoạn 2 tuần) và $30 \%$ đến $80 \%$ (ở giai đoạn 4 tuần); chiều cao của chồi tăng từ $14,51 \%$ đến $37,09 \%$ (giai đoạn 2 tuần tuổi) và $25,40 \%$ đến $50,27 \%$ (giai đoạn 4 tuần tuổi). Trong đó, môi trường có bổ sung kinetin $1,5 \mathrm{mg} / \mathrm{l}$ có khả năng tạo chồi và kích thích sinh trưởng chồi lớn nhất, số chồi/mẫu đạt 1,88 (giai đoạn 2 tuần) và 1,98 (giai đoạn 4 tuần), hệ số nhân chồi tăng $80 \%$ so với đối chứng (giai đoạn 4 tuần); kích thước của chồi đạt 0,85 $\mathrm{cm}$ (giai đoạn 2 tuần) và $2,78 \mathrm{~cm}$ (giai đoạn 4 tuần) tăng $37,09 \%$ đến $50,27 \%$ so với đối chứng. Khi nồng độ kinetin cao hơn $1,5 \mathrm{mg} / \mathrm{l}$ thì hệ số nhân chồi và chiều cao chồi giảm dần.

\subsection{Anh hưởng kinetin và ảnh hưởng kết hợp của kinetin tối ưu với IBA đến sự phát sinh và} sinh trưởng chồi tù̀ đoạn thân mang mắt chồi bên của cây Thổ nhân sâm chuyển gen GmCHI

Kết quả phân tích ảnh hưởng của kinetin đến sự phát sinh và sinh trưởng chồi từ đoạn thân mang mắt chồi bên được trình bày ở bảng 2 .

Bảng 2 cho thấy, môi trường MS bổ sung kinetin $0,5-2,5 \mathrm{mg} / \mathrm{l}$ thì cho số chồi tăng so với đối chứng từ $26,51 \%$ đến $77,27 \%$ (ở giai đoạn 2 tuần) và $32,14 \%$ đến $80 \%$ (ở giai đoạn 4 tuần); chiều cao của chồi tăng từ $8,69 \%$ đến $24,63 \%$ (giai đoạn 2 tuần) và $13,44 \%$ đến $40,86 \%$ (giai đoạn 4 tuần). Trong đó, môi trường có bổ sung kinetin $1,5 \mathrm{mg} / \mathrm{l}$ có khả năng tạo chồi và kích thích sinh trưởng chồi lớn nhất, số chồi/mẫu đạt 2,34 (giai đoạn 2 tuần) và 2,52 (giai đoạn 4 tuần), hệ số nhân chồi tăng $80 \%$ so với đối chứng; kích thước trung bình của chồi đạt $0,86 \mathrm{~cm}$ (giai đoạn 2 tuần) và $2,62 \mathrm{~cm}$ (giai đoạn 4 tuần) tăng $24,63 \%$ và $40,86 \%$ so với đối chứng.

Khi nồng độ kinetin cao hơn $1,5 \mathrm{mg} / \mathrm{l}$ thì hệ số nhân chồi và chiều cao chồi giảm dần. So sánh kết quả ở bảng 1 và bảng 2 cho thấy, sự phát sinh và sinh trưởng chồi từ đoạn thân mang mắt chồi bên hiệu quả hơn sự phát sinh và sinh trưởng chồi từ nách lá mầm ở cùng nồng độ kinetin. Vậy đoạn thân mang mắt chồi bên là vật liệu thích hợp để tạo đa chồi ở cây Thổ nhân sâm chuyển gen. Kết quả nghiên cứu này phù hợp nghiên cứu [6].

Kết quả ảnh hưởng tổ hợp $1,5 \mathrm{mg} / 1$ kinetin và IBA đến sự phát sinh, sinh trưởng chồi từ đoạn thân mang mắt chồi bên được trình bày ở bảng 3 và hình 1 . 
Bảng 2. Anh hương của kinetin đến sự phát sinh và sinh trương chồi tù̀ đoạn thân mang mắt chồi bên (n=30)

\begin{tabular}{|c|c|c|c|c|c|}
\hline $\begin{array}{c}\text { Nồng độ kinetin } \\
(\mathbf{m g} / \mathbf{l})\end{array}$ & $\begin{array}{c}\text { Số chồi/ } \\
\text { mấu }\end{array}$ & $\begin{array}{l}\text { \% so với } \\
\text { ĐC }\end{array}$ & $\begin{array}{c}\text { Chiều cao chồi } \\
\text { (cm) }\end{array}$ & $\begin{array}{l}\text { Số lá/ } \\
\text { chồi }\end{array}$ & $\begin{array}{c}\text { Chất lượng } \\
\text { chồi }\end{array}$ \\
\hline \multicolumn{6}{|c|}{ Sau 2 tuần } \\
\hline 0 & $1,32 \pm 0,22$ & 100 & $0,69 \pm 0,18$ & $2,57 \pm 0,19$ & $\mathrm{~K}$ \\
\hline 0,5 & $1,67 \pm 0,15$ & 126,51 & $0,75 \pm 0,14$ & $3,45 \pm 0,21$ & TB \\
\hline 1,0 & $1,98 \pm 0,23$ & 150,00 & $0,79 \pm 0,18$ & $3,63 \pm 0,19$ & TB \\
\hline 1,5 & $2,34 \pm 0,24$ & 177,27 & $0,86 \pm 0,19$ & $3,86 \pm 0,22$ & $\mathrm{~T}$ \\
\hline 2,0 & $2,19 \pm 0,13$ & 165,90 & $0,82 \pm 0,17$ & $3,78 \pm 0,23$ & $\mathrm{~T}$ \\
\hline 2,5 & $2,01 \pm 0,16$ & 152,27 & $0,78 \pm 0,19$ & $3,72 \pm 0,19$ & TB \\
\hline \multicolumn{6}{|c|}{ Sau 4 tuần } \\
\hline 0 & $1,40 \pm 0,16$ & 100 & $1,86+0,19$ & $4,65 \pm 0,19$ & $\mathrm{~K}$ \\
\hline 0,5 & $1,85 \pm 0,19$ & 132,14 & $2,11 \pm 0,21$ & $4,98 \pm 0,18$ & $\mathrm{~TB}$ \\
\hline 1,0 & $2,02 \pm 0,22$ & 144,28 & $2,45 \pm 0,21$ & $5,02 \pm 0,21$ & $\mathrm{~TB}$ \\
\hline 1,5 & $2,52 \pm 0,17$ & 180,00 & $2,62 \pm 0,19$ & $5,45 \pm 0,19$ & $\mathrm{~T}$ \\
\hline 2,0 & $2,45 \pm 0,22$ & 175,00 & $2,56 \pm 0,18$ & $5,39 \pm 0,22$ & $\mathrm{~T}$ \\
\hline 2,5 & $2,34 \pm 0,19$ & 167,14 & $2,49 \pm 0,22$ & $5,11 \pm 0,23$ & TB \\
\hline
\end{tabular}

Chú thích: T: chồi tốt; K: chồi kém; TB: chồi trung bình

Bảng 3. Anh hưởng của tổ hợp 1,5 mg/l kinetin và IBA đến sụ phát sinh, sinh trương chồi tù đoạn thân mang mắt chồi bên $(n=30)$

\begin{tabular}{|c|c|c|c|c|c|c|}
\hline $\begin{array}{l}\text { Nồng độ } \\
\text { kinetin } \\
\text { (mg/l) }\end{array}$ & $\begin{array}{c}\text { Nồng độ } \\
\text { IBA } \\
(\mathrm{mg} / \mathrm{l})\end{array}$ & Số chồi/mẫu & $\begin{array}{c}\% \text { so } \\
\text { vói ĐC }\end{array}$ & $\begin{array}{l}\text { Chiều cao } \\
\text { chồi }(\mathrm{cm})\end{array}$ & Số lá/chồi & Chất lượng chồi \\
\hline & \multicolumn{6}{|c|}{ Sau 2 tuần } \\
\hline \multirow{7}{*}{1,5} & 0 & $2,34 \pm 0,24$ & 100 & $0,86 \pm 0,19$ & $3,86 \pm 0,22$ & Mập, xanh bình thường \\
\hline & 0,2 & $2,42 \pm 0,17$ & 103,42 & $0,87 \pm 0,14$ & $3,90 \pm 0,18$ & Mập, xanh bình thường \\
\hline & 0,4 & $2,55 \pm 0,19$ & 108,97 & $0,89 \pm 0,22$ & $3,92 \pm 0,19$ & Mập, xanh bình thường \\
\hline & 0,6 & $2,60 \pm 0,22$ & 111,11 & $0,91 \pm 0,18$ & $4,12 \pm 0,21$ & Mập, xanh bình thường \\
\hline & 0,8 & $2,78 \pm 0,16$ & 118,80 & $0,95 \pm 0,19$ & $4,21 \pm 0,22$ & Mập, xanh bình thường \\
\hline & 1,0 & $2,70 \pm 0,21$ & 115,38 & $0,92 \pm 0,21$ & $4,15 \pm 0,19$ & Gầy, vàng \\
\hline & 1,2 & $2,55 \pm 0,22$ & 108,97 & $0,88 \pm 0,22$ & $4,02 \pm 0,21$ & Gầy, vàng \\
\hline \multirow{8}{*}{1,5} & \multicolumn{6}{|c|}{ Sau 4 tuần } \\
\hline & 0 & $2,52 \pm 0,17$ & 100 & $2,62 \pm 0,19$ & $5,45 \pm 0,19$ & Mập, xanh bình thường \\
\hline & 0,2 & $2,62 \pm 0,12$ & 103,96 & $2,78 \pm 0,17$ & $5,55 \pm 0,21$ & Mập, xanh bình thường \\
\hline & 0,4 & $2,78 \pm 0,16$ & 110,32 & $2,99 \pm 0,19$ & $5,75 \pm 0,17$ & Mập, xanh bình thường \\
\hline & 0,6 & $2,83 \pm 0,17$ & 112,30 & $3,02 \pm 0,15$ & $5,78 \pm 0,14$ & Mập, xanh bình thường \\
\hline & 0,8 & $2,90 \pm 0,14$ & 115,08 & $3,10 \pm 0,14$ & $5,82 \pm 0,21$ & Mập, xanh bình thường \\
\hline & 1,0 & $2,79 \pm 0,22$ & 110,71 & $3,04 \pm 0,21$ & $5,76 \pm 0,19$ & Gầy, vàng \\
\hline & 1,2 & $2,65 \pm 0,21$ & 105,16 & $2,97 \pm 0,23$ & $5,65 \pm 0,18$ & Gầy, vàng \\
\hline
\end{tabular}

Hình 1. Anh hương của kinetin kết hợp với IBA đến sụ phát sinh và sinh trưởng của chồi tù đoạn thân mang mắt chồi bên. A, B: Anh hwởng của kinetin 1,5 mg/l kết hợp IBA 0,8 mg/l đến sư phát sinh và sinh truởng chồi tù̀ đoạn thân mang mắt chồi bên sau 2 tuần và sau 4 tuần 
Kết quả ở bảng 3 và hình 1 cho thấy, môi trường bổ sung $1,5 \mathrm{mg} / \mathrm{l}$ kinetin kết hợp với IBA ở các nồng nồng độ từ $0,2-1,2 \mathrm{mg} / \mathrm{l}$ cho số chồi tăng so với đối chứng từ $3,42 \%$ đến $18,8 \%$ (ở giai đoạn 2 tuần) và 3,96\% đến $15,08 \%$ (ở giai đoạn 4 tuần); tuy nhiên, chiều cao của chồi tăng không đáng kể so với đối chứng. Trong đó, môi trường có bổ sung $1,5 \mathrm{mg} / \mathrm{l}$ kinetin kết hợp $0,8 \mathrm{mg} / \mathrm{l}$ IBA có khả năng tạo chồi và kích thích sinh trưởng chồi lớn nhất, số chồi/mẫu đạt 2,78 (giai đoạn 2 tuần) và 2,90 (giai đoạn 4 tuần), hệ số nhân chồi tăng $15,08 \%$ so với đối chứng; kích thước trung bình của chồi đạt $0,95 \mathrm{~cm}$ (giai đoạn 2 tuần) và $3,10 \mathrm{~cm}$ (giai đoạn 4 tuần) tăng $10,46 \%$ và $18,32 \%$ so với đối chứng. Như vậy, khi môi trường bổ sung $1,5 \mathrm{mg} / \mathrm{l}$ kinetin kết hợp với $0,8 \mathrm{mg} / \mathrm{l}$ IBA cho hiệu quả tạo đa chồi tốt hơn khi chỉ bổ sung $1,5 \mathrm{mg} / \mathrm{l}$ kinetin.

\subsection{Anh hưởng BAP và ảnh hưởng kết hợp của BAP tối ưu với IBA đến sụ phát sinh và sinh trưởng chồi từ đọ̣n thân mang mắt chồi bên của cây Thổ nhân sâm chuyển gen GmCHI}

Kết quả phân tích ảnh hưởng của BAP đến sự phát sinh và sinh trưởng chồi từ đoạn thân mang mắt chồi bên được trình bày ở bảng 4 và hình 2 .

Bảng 4. Anh hương của BAP đến sụ phát sinh và sinh trương chồi tù đoạn thân mang mắt chồi bên (n=30)

\begin{tabular}{|c|c|c|c|c|c|}
\hline $\begin{array}{c}\text { Nồng độ BAP } \\
\text { (mg/l) }\end{array}$ & $\begin{array}{c}\text { Số chồi/ } \\
\text { mấu }\end{array}$ & $\begin{array}{c}\text { \% so với } \\
\text { ĐC }\end{array}$ & $\begin{array}{l}\text { Chiều cao } \\
\text { chồi }(\mathrm{cm})\end{array}$ & $\begin{array}{c}\text { Số lá/ } \\
\text { chồi }\end{array}$ & $\begin{array}{c}\text { Chất lượng } \\
\text { chồi }\end{array}$ \\
\hline \multicolumn{6}{|c|}{ Sau 2 tuần } \\
\hline 0 & $1,37 \pm 0,15$ & 100 & $0,69 \pm 0,15$ & $3,07 \pm 0,17$ & Gầy, vàng \\
\hline 0,5 & $1,85 \pm 0,19$ & 135,04 & $0,75 \pm 0,18$ & $4,24 \pm 0,16$ & Gầy, vàng \\
\hline 1,0 & $2,31 \pm 0,21$ & 168,61 & $0,84 \pm 0,21$ & $4,55 \pm 0,21$ & Gầy, vàng \\
\hline 1,5 & $2,41 \pm 0,14$ & 175,91 & $0,85 \pm 0,17$ & $4,77 \pm 0,19$ & Mập, XBT \\
\hline 2,0 & $3,1 \pm 0,18$ & 226,28 & $0,89 \pm 0,19$ & $5,20 \pm 0,18$ & Mập, XBT \\
\hline 2,5 & $2,82 \pm 0,23$ & 205,83 & $0,84 \pm 0,13$ & $5,10 \pm 0,15$ & Mập, XBT \\
\hline 3,0 & $2,79 \pm 0,17$ & 203,64 & $0,79 \pm 0,18$ & $4,89 \pm 0,14$ & Gầy, vàng \\
\hline \multicolumn{6}{|c|}{ Sau 4 tuần } \\
\hline 0 & $1,49 \pm 0,22$ & 100 & $1,94 \pm 0,19$ & $5,70 \pm 0,22$ & Gầy, vàng \\
\hline 0,5 & $2,13 \pm 0,20$ & 142,95 & $2,57 \pm 0,21$ & $5,88 \pm 0,23$ & Gầy, vàng \\
\hline 1,0 & $2,50 \pm 0,23$ & 167,78 & $2,63 \pm 0,22$ & $5,94 \pm 0,19$ & Gầy, vàng \\
\hline 1,5 & $2,88 \pm 0,17$ & 193,29 & $2,80 \pm 0,20$ & $6,20 \pm 0,21$ & Mập, XBT \\
\hline 2,0 & $3,23 \pm 0,24$ & 216,77 & $2,90 \pm 0,18$ & $6,55 \pm 0,18$ & Mập, XBT \\
\hline 2,5 & $2,89 \pm 0,16$ & 193,96 & $2,64 \pm 0,17$ & $6,19 \pm 0,17$ & Mập, XBT \\
\hline 3,0 & $2,84 \pm 0,18$ & 190,60 & $2,46 \pm 0,15$ & $5,90 \pm 0,20$ & Gầy, vàng \\
\hline
\end{tabular}

$X B T$ : xanh bìn thuòng

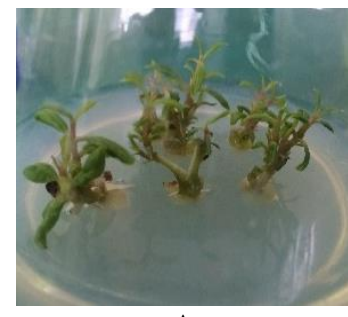

A

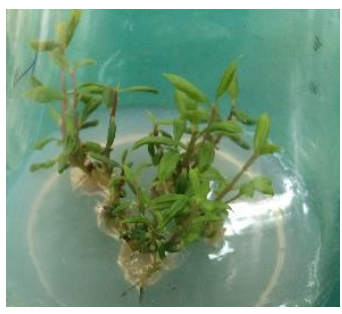

$\mathrm{B}$

Hình 2. Anh hương của BAP đến sự phát sinh và sinh trương của chồi tù đoạn thân mang mắt chồi bên. A, B: Anh hường của BAP 2,0 mg/l đến sự phát sinh và sinh trương chồi tù đoạn thân mang mắt chồi bên sau 2 tuần và 4 tuần

Kết quả ở bảng 4 và hình 2 cho thấy, môi trường MS cơ bản bổ sung $0,5-3,0 \mathrm{mg} / \mathrm{l} \mathrm{BAP}$ cho số chồi tăng so với đối chứng từ $35,04 \%$ đến $126,28 \%$ (ở giai đoạn 2 tuần) và $42,95 \%$ đến $116,77 \%$ (ở giai đoạn 4 tuần); chiều cao của chồi tăng từ $8,6 \%$ đến $28,98 \%$ (giai đoạn 2 tuần) và $32,47 \%$ đến 49,48\% (giai đoạn 4 tuần). Trong đó, môi trường có bổ sung $2 \mathrm{mg} / \mathrm{l} \mathrm{BAP}$ có khả năng tạo chồi và kích thích sinh trưởng chồi lớn nhất, số chồi/mẫu đạt 3,1 (giai đoạn 2 tuần) và 
3,23 (giai đoạn 4 tuần), kích thước trung bình của chồi đạt $0,89 \mathrm{~cm}$ (giai đoạn 2 tuần) và $2,9 \mathrm{~cm}$ (giai đoạn 4 tuần) tăng $28,98 \%$ và $49,48 \%$ so với đối chứng. Khi nồng độ BAP cao hơn $2,0 \mathrm{mg} / \mathrm{l}$ thì hệ số nhân chồi và chiều cao chồi giảm dần.

Kết quả phân tích ảnh hưởng của sự kết hợp giữa $\mathrm{BAP}$ và $\mathrm{IBA}$ đến sự phát sinh và sinh trưởng chồi từ đoạn thân mang mắt chồi bên cho thây, môi trường bổ sung BAP 2,0 mg/l kết hợp với IBA ở các nồng nồng độ từ $0,2-1,2 \mathrm{mg} / \mathrm{l}$ cho số chồi không tăng so với đối chứng là $\mathrm{BAP} 2 \mathrm{mg} / \mathrm{l}$ không bổ sung IBA; đồng thời chiều cao của chồi không tăng so với đối chứng, chồi gầy và có màu vàng (Hình 3$)$.

Kết quả của nghiên cứu này phù hợp với nghiên cứu [6] khi nghiên cứu hiệu quả tạo đa chồi ở cây Thổ nhân sâm chưa chuyển gen.

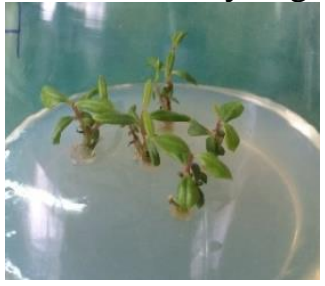

A

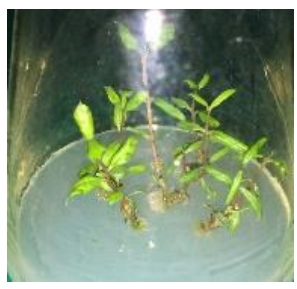

B

Hình 3. Anh hương của BAP kết hợp với IBA đến sụ phát sinh và sinh trương của chồi tù đoạn thân mang mắt chồi bên. A, B: Ảnh hương của BAP 2,0 mg/l kết hợp IBA $0,6 \mathrm{mg} / \mathrm{l}$ đến sự phát sinh và sinh trương chồi tù đoạn thân mang mắt chồi bên sau 2 tuần và 4 tuần

Từ kết quả ở bảng 3 và bảng 4 cho thấy, môi trường bổ sung $2 \mathrm{mg} / \mathrm{l}$ BAP cho hiệu quả đa chồi cao hơn $11,5 \%$ (ở giai đoạn 2 tuần tuổi) và $11,38 \%$ (giai đoạn 4 tuần tuổi) và chồi to khỏe hơn so với môi trường bồ sung $1,5 \mathrm{mg} /$ kinetin kết hợp $0,8 \mathrm{mg} / \mathrm{l} \mathrm{IBA}$. Như vậy, môi trường $\mathrm{MS}$ cơ bản bổ sung $2 \mathrm{mg} / \mathrm{l}$ BAP cho hiệu quả đa chồi tốt nhất ở cây Thổ nhân sâm chuyển gen $G m C H I$.

\subsection{Kết quả nghiên cứu ảnh hưởng kết hợp $0,5 \mathrm{mg} / \mathrm{l}$ IAA và $0,5 \mathrm{mg} / \mathrm{l}$ NAA với kinetin đến khả năng ra rê̂́ của cây Thổ nhân sâm chuyển gen GmCHI}

Kết quả phân tích ảnh hưởng kết hợp của kinetin với $0,5 \mathrm{mg} / \mathrm{l}$ IAA đến khả năng ra rễ của cây Thổ nhân sâm chuyển gen được trình bày ở bảng 5 và hình 4 . Kết quả cho thấy, khi bổ sung vào môi trường nuôi cấy $0,5 \mathrm{mg} / \mathrm{l}$ IAA kết hợp kinetin $0,3-1,1 \mathrm{mg} / \mathrm{l}$ thì khả năng tạo rễ của cây Thổ nhân sâm chuyển gen $G m C H I$ đều thấp hơn so với đối chứng (chỉ bổ sung $0,5 \mathrm{mg} / \mathrm{l} \mathrm{IAA}$ ). Ở môi trường bổ sung $0,5 \mathrm{mg} / \mathrm{l} \mathrm{IAA}$ cho tỷ lệ cây ra rễ cao nhất đạt $82,11 \%$ (giai đoạn 2 tuần) và $97,63 \%$ (ở giai đoạn 4 tuần). Số rễ là 5,67 (giai đoạn 2 tuần) và 13,78 (giai đoạn 4 tuần). Nhưng khi kết hợp với kinetin làm các tỷ lệ này giảm xuống. Vậy $0,5 \mathrm{mg} / \mathrm{l}$ IAA là nồng độ thích hợp kích thích ra rễ ở cây Thổ nhân sâm chuyển gen $G m C H I$.

Kết quả phân tích ảnh hưởng của $0,5 \mathrm{mg} / \mathrm{l}$ NAA kết hợp kinetin $0,3-1,1 \mathrm{mg} / 1$ đến khả năng ra rễ của cây Thổ nhân sâm chuyển gen cho thấy, khi bổ sung vào môi trường nuôi cấy $0,5 \mathrm{mg} / \mathrm{l}$ NAA kết hợp kinetin $0,3-1,1 \mathrm{mg} / \mathrm{l}$ thì khả năng tạo rễ của cây Thổ nhân sâm chuyển gen đều thấp hơn so với đối chứng (chỉ bổ sung $0,5 \mathrm{mg} / \mathrm{l} \mathrm{NAA}$ ). Ở môi trường bổ sung NAA $0,5 \mathrm{mg} / \mathrm{l}$ cho tỷ lệ cây ra rễ cao nhất đạt $60,02 \%$ (giai đoạn 2 tuần) và $89,69 \%$ (ở giai đoạn 4 tuần). Số rễ là 3,32 (giai đoạn 2 tuần) và 10,03 (giai đoạn 4 tuần). Nhưng khi kết hợp với kinetin làm các tỷ lệ này giảm xuống. Vậy nồng độ NAA thích hợp kích thích ra rễ ở cây Thổ nhân sâm chuyển gen là 0,5 mg/l (Bảng 6). 
Bảng 5. Anh hương của 0,5 mg/l IAA kết hợp kinetin đến khả năng ra rễ của cây Thổ nhân sâm chuyển gen $\mathrm{GmCHI}(n=30)$

\begin{tabular}{|c|c|c|c|c|c|}
\hline $\begin{array}{c}\text { Nồng độ IAA } \\
\text { (mg/l) }\end{array}$ & $\begin{array}{c}\text { Nồng độ kinetin } \\
\text { (mg/l) }\end{array}$ & $\begin{array}{c}\text { Tỷ lệ chồi ra } \\
\text { rễ̂ }(\%)\end{array}$ & $\begin{array}{l}\text { Số rễ̂̀ } \\
\text { chồi }\end{array}$ & $\begin{array}{c}\text { Chiều dài rễ } \\
(\mathbf{c m})\end{array}$ & $\begin{array}{c}\text { Chất } \\
\text { lượng rễ }\end{array}$ \\
\hline \multicolumn{6}{|c|}{ Sau 2 tuần } \\
\hline \multirow{6}{*}{0,5} & 0 & $82,11 \pm 0,19$ & $5,67 \pm 0,19$ & $0,98 \pm 0,22$ & $\mathrm{~T}$ \\
\hline & 0,3 & $76,67 \pm 0,15$ & $4,16 \pm 0,21$ & $0,79 \pm 0,19$ & $\mathrm{~T}$ \\
\hline & 0,5 & $70,12 \pm 0,21$ & $3,92 \pm 0,17$ & $0,71 \pm 0,21$ & $\mathrm{~T}$ \\
\hline & 0,7 & $68,23 \pm 0,17$ & $3,34 \pm 0,23$ & $0,67 \pm 0,24$ & TB \\
\hline & 0,9 & $63,12 \pm 0,16$ & $2,98 \pm 0,25$ & $0,59 \pm 0,17$ & TB \\
\hline & 1,1 & $45,12 \pm 0,18$ & $2,51 \pm 0,21$ & $0,51 \pm 0,16$ & TB \\
\hline \multicolumn{6}{|c|}{ Sau 4 tuần } \\
\hline \multirow{6}{*}{0,5} & 0 & $97,63 \pm 0,15$ & $13,78 \pm 0,21$ & $3,69 \pm 0,22$ & $\mathrm{~T}$ \\
\hline & 0,3 & $84,14 \pm 0,22$ & $10,31 \pm 0,22$ & $3,02 \pm 0,23$ & $\mathrm{~T}$ \\
\hline & 0,5 & $78,23 \pm 0,19$ & $10,01 \pm 0,14$ & $2,79 \pm 0,16$ & $\mathrm{~T}$ \\
\hline & 0,7 & $72,67 \pm 0,22$ & $9,23 \pm 0,22$ & $2,53 \pm 0,21$ & TB \\
\hline & 0,9 & $69,86 \pm 0,21$ & $8,78 \pm 0,19$ & $2,47 \pm 0,19$ & TB \\
\hline & 1,1 & $54,43 \pm 0,17$ & $8,34 \pm 0,17$ & $2,05 \pm 0,22$ & TB \\
\hline
\end{tabular}

Chú thích: T: chồi tốt; K: chồi kém; TB: chồi trung bình

Bảng 6. Anh hương của 0,5 mg/l NAA kết hợp kinetin đến khả năng ra rễ của cây Thổ nhân sâm chuyển gen GmCHI $(n=30)$

\begin{tabular}{|c|c|c|c|c|}
\hline $\begin{array}{c}\text { Nồng độ NAA } \\
\text { (mg/l) }\end{array}$ & $\begin{array}{l}\text { Nồng độ kinetin } \\
\text { (mg/l) }\end{array}$ & $\begin{array}{c}\text { Tỷ lệ chồi ra rễ } \\
(\%)\end{array}$ & Số rễ̂/chồi & Chiều dài rễ $(\mathrm{cm})$ \\
\hline & \multicolumn{4}{|c|}{ Sau 2 tuần } \\
\hline \multirow{6}{*}{0,5} & 0 & $60,02 \pm 0,21$ & $3,32 \pm 0,22$ & $0,35 \pm 0,21$ \\
\hline & 0,3 & $59,45 \pm 0,19$ & $3,04 \pm 0,19$ & $0,29 \pm 0,23$ \\
\hline & 0,5 & $56,21 \pm 0,18$ & $2,78 \pm 0,17$ & $0,25 \pm 0,19$ \\
\hline & 0,7 & $51,21 \pm 0,22$ & $2,54 \pm 0,23$ & $0,19 \pm 0,17$ \\
\hline & 0,9 & $47,32 \pm 0,17$ & $2,34 \pm 0,18$ & $0,17 \pm 0,24$ \\
\hline & 1,1 & $40,34 \pm 0,19$ & $2,02 \pm 0,16$ & $0,13 \pm 0,18$ \\
\hline & \multicolumn{4}{|c|}{ Sau 4 tuần } \\
\hline \multirow{6}{*}{0,5} & 0 & $89,69 \pm 0,19$ & $10,03 \pm 0,23$ & $2,86 \pm 0,22$ \\
\hline & 0,3 & $82,45 \pm 0,16$ & $9,78 \pm 0,21$ & $2,79 \pm 0,21$ \\
\hline & 0,5 & $79,78 \pm 0,21$ & $9,45 \pm 0,20$ & $2,73 \pm 0,16$ \\
\hline & 0,7 & $75,58 \pm 0,17$ & $8,98 \pm 0,18$ & $2,61 \pm 0,21$ \\
\hline & 0,9 & $72,45 \pm 0,15$ & $8,67 \pm 0,15$ & $2,45 \pm 0,23$ \\
\hline & 1,1 & $70,02 \pm 0,22$ & $8,55 \pm 0,17$ & $1,98 \pm 0,19$ \\
\hline
\end{tabular}

Khi so sánh các chỉ tiêu về tỷ lệ ra rễ và số rễ ở cùng thời điểm của 2 nồng độ tối ưu IAA 0,5 $\mathrm{mg} / \mathrm{l}$ và NAA $0,5 \mathrm{mg} / \mathrm{l}$ thì thấy rằng IAA hiệu quả hơn NAA rất nhiều. Ở nồng độ $\mathrm{IAA} 0,5 \mathrm{mg} / \mathrm{l}$ cho tỷ lệ cây ra rễ đạt $82,11 \%$ (giai đoạn 2 tuần) cao hơn 1,33 lần và $97,63 \%$ (ở giai đoạn 4 tuần) cao hơn 1,02 lần so với NAA ở cùng thời điểm; số rễ là 5,67 (giai đoạn 2 tuần) cao hơn 1,71 lần so với NAA. Vậy chất kích thích ra rễ tối ưu ở cây Thổ nhân sâm chuyển gen là IAA 0,5 mg/l. Kết quả nghiên cứu này phù hợp với nghiên cứu [6]. 


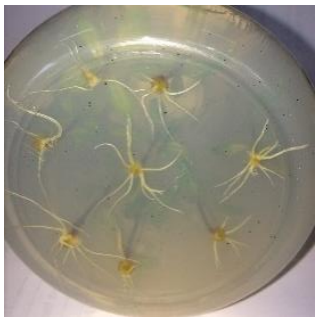

A

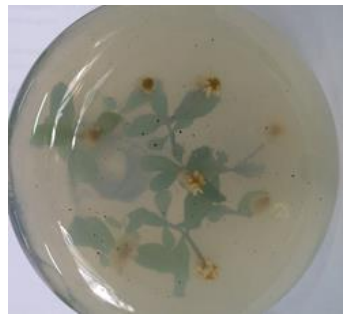

$\mathrm{B}$

Hình 4. Ảnh hưởng của kinetin kết hợp với 0,5 mg/l IAA đến khả năng ra rễ của cây Thổ nhân sâm chuyển gen GmCHI. A: Anh hưởng của 0,5 mg/l IAA đến khả năng ra rễ của cây Thổ nhân sâm chuyển gen GmCHI; B: Anh hưởng kết hợp 0,5 mg/l IAA với 1,1 mg/l kinetin đến khả năng ra rễ của cây Thổ nhân sâm chuyển gen $\mathrm{GmCHI}$

\section{Kết luận}

Ở cây Thổ nhân sâm chuyển gen $G m C H I$, đoạn thân mang mắt chồi bên là vật liệu thích hợp để tạo đa chồi khi sử dụng môi trường MS cơ bản bổ sung kinetin. Bổ sung 2,0 mg/l BAP cho hiệu quả đa chồi cao hơn so với bổ sung $1,5 \mathrm{mg} / \mathrm{l}$ kinetin hay kết hợp $1,5 \mathrm{mg} / \mathrm{l}$ kinetin với $0,8 \mathrm{mg} / 1$ IBA. Sử dụng $0,5 \mathrm{mg} / \mathrm{l}$ IAA có khả năng tạo rễ tốt hơn so với kết hợp $0,5 \mathrm{mg} / \mathrm{l} \mathrm{IAA}$ với kinetin.

\section{TÀI LIỆU THAM KHẢO/ REFERENCES}

[1] T. Catthareeya, P. Papirom, S. Chanlun, and S. Kupittayanant, "Talinum paniculatum (Jacq.) Gertn: A medicinal plant with potential estrogenic activity in ovariectomized rats," Int J Pharm Pharm Sci, vol. 5, pp. 478-485, 2013.

[2] Y. S. W. Manuhara, A. Yachya, and A. N. Kristanti, "Effect of aeration and inoculum density on biomass and saponin content of Talinum paniculatum Gaertn. hairy roots in balloon-type bubble bioreactor," J Pharm Biomed Sci, vol. 2, no. 4, pp. 47-52, 2012.

[3] T. L. Do, Vietnamese medicinal plants and herbs. Medical publishing house, Ha Noi, 2004.

[4] K. Shashank and K. P. Abhay, "Chemistry and biological activities of flavonoid: An overview," The Scientific World Journal, 2013, Art. no. 162750.

[5] T. N. T. Vu, T. H. T. Le, P. H. Hoang, D. T. Sy, T. T. T. Vu, and H. M. Chu, "Overexpression of the Glycine max chalcone isomerase $(\mathrm{GmCHI})$ gene in transgenic Talinum paniculatum plants," Turk $J$ Bot, vol. 42, pp. 551-558, 2018.

[6] T. N. T. Vu, T. T. Nguyen, and H. M. Chu, "The develoment in vitro regeneration system for gene transfer in Talinum paniculatum plants," TNU Journal of Science and Technology, vol. 161, no. 01, pp. 73-79, 2017.

[7] H. M. Chu, Modern methods of genetic integration in plant breeding. Thai Nguyen university publishing house, 2008. 